\title{
Erratum to: Enhanced Secure Mutual Authentication and Key Agreement Scheme Preserving User Anonymity in Global Mobile Networks
}

\section{Prosanta Gope • Tzonelih Hwang}

Published online: 3 March 2015

(C) Springer Science+Business Media New York 2015

\section{Erratum to: Wireless Pers Commun \\ DOI 10.1007/s11277-015-2344-z}

In the original publication, the figure displayed as Fig. 1 was in fact Fig. 2, and vice versa. The article has been updated to correct this error.

The online version of the original article can be found under doi:10.1007/s11277-015-2344-z.

P. Gope · T. Hwang $(\bowtie)$

National Cheng Kung University, Tainan, Taiwan, ROC

e-mail: hwangtl@ismail.csie.ncku.edu.tw

P. Gope

e-mail: prosanta.nitdgp@gmail.com 